$\infty$

0

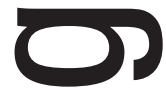

-

ת

1

$\longrightarrow$ 



\title{
ILHAS TÉRMICAS NA CIDADE DE FORTALEZA/CE*
}

\section{THERMAL ISLANDS IN THE CITY OF FORTALEZA/CE}

\author{
Marcelo de Oliveira Moura - UFC \\ geommoura@yahoo.com.br \\ Maria Elisa Zanella - UFC \\ elisazv@terra.com.br \\ Marta Celina Linhares Sales - UFC \\ mclsales@uol.com.br
}

\section{RESUMO}

0 objetivo do trabalho se constitui em caracterizar o clima produzido pela cidade de Fortaleza, sob o nível termodinâmico do S.C.U. (MONTEIRO, 1976) numa dimensão linear tendo como referência doze pontos experimentais representativos da realidade urbana. Para isso, houve a realização de dois experimentos de regimes sazonais diferenciados com registros horários e simultâneos em perfis de 24 horas (07 às 06 horas). 0 primeiro experimento realizado no outono austral, período da quadra chuvosa na região, nos dias 04 e 05/05/2007, e 0 segundo na primavera, período da quadra seca, nos dias 09 e 10/11/2007. Os resultados encontrados seguem 0 ritmo da habitualidade climática dos episódios sazonais analisados, sendo os sistemas de circulação atmosférica fatores determinantes no comportamento térmico da cidade. A pesquisa identificou que as ilhas de calor em Fortaleza podem ultrapassar 0 valor de $5^{\circ} \mathrm{C}$, e ocorrem com maior freqüência e intensidade no período diurno, entre as 07 e 15 horas. As espacializações das ilhas de calor se concentraram nos setores sudoeste, oeste, noroeste e porção central da cidade.

Palavras chave: clima urbano, ilhas térmicas, Fortaleza.

\section{ABSTRACT}

The objective of the work is constituted in characterizing the climate produced by the city of Fortaleza, under the level thermodynamic of the S.C.U. (MONTEIRO, 1976) in a linear dimension taking as a reference twelve experimental representative points of the urbane reality. For that there was the realization of two experiments in seasonal regimes differentiated with registers time-tables and simultaneous in profiles of 24 hours (7 at 6 hours). The first thing carried out in the southern autumn, period of the rainy block in the region, in the days 04 and $05 / 05 / 2007$ and according to in the spring, period of the dry block, in the days 09 and 11/10/2007. The considered results follow the rhythm of the climatic of the seasonal analysed episodes, being the systems of atmospheric circulation determinative factors in the thermal behaviour of the city.The inquiry identified that the islands of heat in Fortaleza can exceed the value of $5^{\circ} \mathrm{C}$ and take place with bigger frequency and intensity in the daytime period between 7 and 15 hours. The specializations of the islands of heat concentrated on the sectors south-west, west, northwest and central portion of the city.

Key-words: urbane climate, thermal islands, Fortaleza

\begin{tabular}{|l|c|c|c|c|c|c|}
\hline Boletim Goiano de Geografia & Goiânia - Goiás - Brasil & v. 28 & n. 2 & p. 33-44 & jul. / dez. & 2008 \\
\hline
\end{tabular}





\section{Introdução}

A cidade de Fortaleza (Figura 1), localizada na faixa central da zona litorânea do Estado do Cear,á na região do Nordeste do Brasil, apresenta uma série de problemas ambientais de descaracterização e degradação de seus componentes naturais, o que vem comprometendo a qualidade de vida de seus habitantes. O crescimento desordenado do município, acompanhado de uma série histórica de políticas urbanas pontuais e ambientalmente excludentes, constitui o tensor de destaque desse quadro.

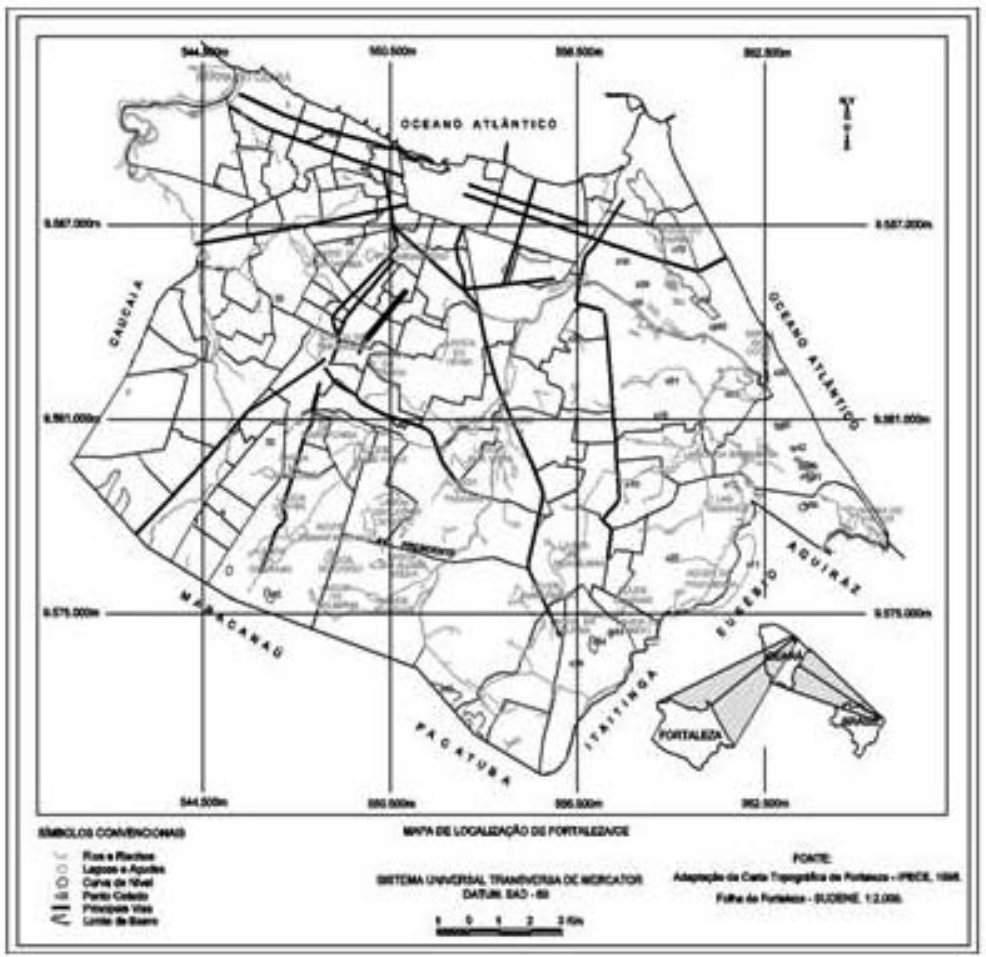

Figura 1 - Localização da área de estudo

A modificação do clima original de Fortaleza faz parte dessa realidade, mas não representa uma problemática de primeira ordem. Entretanto, existem dados alarmantes, como a regressão de 50\% da taxa da velocidade do vento (Xavier, 1996 e 2001), suficientes para induzir novos planos ur- 
banos e sensibilizar a sociedade para a tomada de decisões de controle dos atributos climáticos urbanos.

Existem diversos trabalhos (Projeto Tempofor, 1990; Maia et al. 1996; Santana, 1997 e 2003; Xavier, 1996 e 2001; Pétalas, 2000; Malveira, 1998 e 2003; Hissa, 2002; Zanella \& Claudino-Sales 2002) referentes aos estudos de clima urbano de Fortaleza, com diversidade metodológica e aprofundamentos diferenciados realizados por diferentes áreas do conhecimento, todos voltados para a compreensão do comportamento térmico da cidade (Moura, 2006). No entanto, nenhum estudo tratou o assunto considerando experimentos diários de leituras horárias com episódios sazonais contrastantes, além de análises na compreensão da dinâmica atmosférica regional e seus reflexos sobre o clima local.

O objetivo desse trabalho se constitui em definir a freqüência e a intensidade das ilhas térmicas (ilhas de calor e frescor) nas realidades intra e inter-urbanas de Fortaleza tendo como referência pontos experimentais representativos da realidade urbana.

\section{Ilhas térmicas: abordagem conceitual}

O conceito de ilhas térmicas adotado neste trabalho é uma referência às configurações espaciais e temporais das ilhas de calor e das ilhas de frio ou frescor. As ilhas térmicas são produtos das alterações climáticas provocadas pela urbanização (Oke, 1987; Mendonça, 1994; Pitton, 1997; Moreno 1999). Desse modo, as ilhas térmicas são resultantes do albedo urbano, ou melhor, da mudança dos fluxos de energia solar incidente na superfície da cidade que, conseqüentemente, por meio de processos físicos, produz alterações na temperatura do ar.

O termo ilhas de calor se aplica tanto em um contexto intra-urbano, quando as diferenças da temperatura do ar são realizadas de maneira simultânea, dentro dos limites territoriais da cidade, como no inter-urbano quando as diferenças são obtidas pelo maior valor mensurado na cidade com o valor coletado por um ponto de referencia no meio rural. Já o termo ilhas de frio ou frescor, pouco utilizado pelos trabalhos de climatologia urbana brasileira, é uma referência adotada quando se realiza a diferença do menor valor da temperatura do ar obtido no ambiente urbano com o valor mensurado no meio rural. Quase sempre essa diferença é negativa, por isso os valores se apresentam com o sinal negativo. 
As principais causas que contribuem para a formação das ilhas de calor (Oke, 1987; Mendonça, 1994; Pitton, 1997; Moreno 1999, Malveira, 2003) são resumidas a seguir: 1) Maior armazenamento de calor durante o dia na cidade, graças às propriedades térmicas e caloríficas dos materiais de construção urbana, e sua devolução para a atmosfera durante a noite; 2) Adição do calor antropogênico na área urbana pela utilização de aquecedores e refrigeradores, transporte e atividades industriais; 3) Diminuição do fluxo do calor latente devido ao aumento de superfícies impermeáveis e redução da vegetação e das águas superficiais (lagoas, lagos e rios); 4) Menor perda do calor sensível, causado pela redução da velocidade do vento originada pela edificação e 5) Menores perdas de radiação de ondas longas nos canyons urbanos, devido à redução do "sky view fator" pelos edifícios (método que estima o quanto o céu está "obstruído" por objetos, acima de um ponto qualquer da superfície urbana).

As ilhas térmicas podem ser analisadas sob os aspectos das variações espaciais e temporais, fatores que vão determinar a intensidade e freqüência do fenômeno. As variações espaciais ocorrem tanto no ambiente intraurbano como no inter-urbano e podem ser verificadas nos níveis escalares verticais e horizontais. Há uma tendência das configurações geográficas do fenômeno se apresentarem com maior intensidade da periferia da cidade em direção ao centro, área mais urbanizada.

As variações temporais podem ser verificadas em um ritmo diário, sazonal e intra- anual. Pitton (1997, p.19) coloca que diversos estudos apontam para o maior desenvolvimento das ilhas de calor em noites claras e calmas, já em condições de céu nublado e/ou precipitações e no período diurno a ilha de calor é menos intensa. Entretanto, as pesquisas realizadas nas cidades brasileiras revelam que é no período diurno que ocorrem as maiores intensidades do fenômeno. Na revisão dos trabalhos de clima urbano para o Nordeste do Brasil, realizados por Moura (2008) foi constatada uma tendência das ilhas de calor se configurarem no período da manhã e na situação sazonal de verão e outono, seguida da estação de primavera com intensidades variando entre $1,4^{\circ} \mathrm{C}$ a $8^{\circ} \mathrm{C}$, com valor médio de $3^{\circ} \mathrm{C}$.

\section{Análise do clima urbano de Fortaleza}

\section{A teoria Monteiriana}

A concepção teórica adotada na pesquisa segue as prescrições de Monteiro (1976, 1990 e 2003), onde concebe o Sistema Clima Urbano (S.C.U) um 
sistema singular, aberto, evolutivo, dinâmico, adaptativo e possível de autoregulação que engloba o clima local e sua urbanização. Os níveis que formam a estrutura do S.C.U. podem ser representados por três canais de percepção humana: Canal I- Conforto Térmico; Canal II- Qualidade do Ar; Canal IIIImpacto Meteórico que se associam, respectivamente, aos seguintes níveis de resolução do sistema: termodinâmico, físico-químico e hidrometeórico. Nesse trabalho é adotado o nível Termodinâmico (Canal I - Conforto Térmico) como suporte para análise das configurações térmicas na cidade.

\section{Os controles climáticos urbanos}

O levantamento das condições climáticas urbanas foi obtido em áreas distintas da cidade, que apresentam dinamismo, estrutura urbana e condições geoecológicas diferenciadas. Para isso, foi considerado o material cartográfico específico do sítio da cidade (Hipsometria, Declividade, Cobertura Vegetal, Recursos Hídricos, cartas Percentual de Domicílios - Apartamentos/Residências e Densidade Populacional) em escala de 1:80.000 e aspectos da morfologia e da função urbana observados in situ (rugosidade, porosidade, permeabilidade, tipologia das vias). Todos esses preditores do sítio urbano da cidade formam o que se denomina de controles climáticos urbanos e que em associação aos elementos meteorológicos locais, intitulados de atributos climáticos urbanos, caracterizam o clima da cidade.

Os padrões de ocupação urbana de Fortaleza foram obtido por meio de tratamento digital da imagem SPOT-5 do ano 2004, pelo modo da classificação automática não-supervisionada, resultando numa carta generalizada dos principais padrões de ocupação urbana da cidade e parte dos municípios que fazem fronteira com essa cidade, numa escala de 1:100.000. Com base nessa carta, e considerando outros aspectos de operacionalização de campo foi eleita uma malha de doze pontos para o estudo do clima urbano, aqui chamadas de áreas experimentais, são elas: 1- lagoa da Sapiranga, 2-Cocó, 3Aldeota, 4-Sabiaguaba, 5- Beira-Mar, 6- Centro, 7- Fátima, 8- Barra do Ceará, 9- Henrique Jorge, 10- Damas, 11- Mondubim, 12- Alto Alegre.

\section{Trabalho de Campo}

Seguido da eleição das áreas experimentais, houve a realização de dois experimentos com perfis de 24 horas ( 7 às 6 horas) de episódios com 
registros simultâneos e regimes sazonais diferenciados. O primeiro realizado no outono austral, período da quadra chuvosa na região, nos dias 04 e 05/05/2007, e o segundo, na primavera, período da quadra seca, nos dias 09 e 10/11/2007. Obteve-se oito variáveis: temperatura e umidade relativa do ar, velocidade e direção dos ventos, nebulosidade, tipologia de nuvens, fluxo de veículos e pessoas, além de índices do conforto térmico, obtidos a partir da aplicação de duas escalas (índice Te, Temperatura Efetiva e Conforto Humano pelo Diagrama do INMET). No entatnto, para a presente apresentação, será demosntarato com maior destaque a variável temperatura do ar, elemento de primeira ordem para a compreensão das ilhas térmicas na cidade.

\section{0 ritmo dos atributos climáticos urbanos: configurações das ilhas térmicas na cidade}

A dinâmica atmosférica durante os experimentos

A verificação da circulação atmosférica a nível regional foi relevante para constatar o seu condicionamento sobre as variáveis meteorológicas de escala local. Essa etapa da pesquisa foi realizada por nefanálises das imagens meteorológicas do GOES 10 nos canais do infravermelho e visível, bem como pela interpretação das cartas de pressão ao nível do mar da Marinha do Brasil, ambos com projeção para América do Sul.

No Experimento I, representativo do período chuvoso na cidade, a dinâmica atmosférica revelou um sistema de instabilidade atmosférica de nível mesoescalar provocado pala associação das linhas da ZCIT (Zona de Convergência Intertropical) com linhas de instabilidade. Pela manhã o sistema esteve em formação, sendo mais nítida sua configuração no começo da tarde. À noite há uma maior participação do sistema sobre a cidade e início de sua dissipação munida de convecção. A circulação atmosférica nesse episódio da pesquisa trouxe precipitação para a área de estudo e provocou elevadas taxas de nebulosidade oriundas de nuvens espessas e baixas o que condicionou o comportamento térmico nas áreas experimentais.

O Experimento II, período seco na região, apresentou condições sinóticas de estabilidade atmosférica para todo o dia do episódio. O Sistema Tropical Atlântico, responsável pela produção da mTa (Massa Tropical Atlântica), garantiu nuvens altas do tipo cirruformes, estando o céu em grande parte das observações com nebulosidade não superior a 5/8. Assim como 
no primeiro experimento, a circulação atmosférica condicionou o ritmo dos atributos climáticos locais.

\section{As variações intra e interurbanas das ilhas térmicas em Fortaleza.}

As configurações do campo térmico mostraram que o período de maior aquecimento na cidade ocorreu pela manhã a partir das 9 horas se estendendo até às 17 horas. Fato esse habitual, já que é período que ocorre os maiores picos de radiação solar incidente na superfície, bem como é o período de maior devolução dessa energia para a atmosfera. Dessa forma, as ilhas de calor apresentaram uma tendência de se expressarem mais intensas no período diurno, entre 7 e 15 horas, isso para a realidade intra-urbana de Fortaleza.

No experimento I, as ilhas de calor são mais elevadas nos períodos da manhã e da tarde para o ambiente intra-urbano, com valor de até $4,7^{\circ} \mathrm{C}$, mas é durante a noite e a madrugada que as magnitudes se tornam elevadas para o espaço inter-urbano, com valores entre 3,3 até $4,6{ }^{\circ} \mathrm{C}$ As ilhas de frescor para esse experimento estão presentes até às $17 \mathrm{~h}$ com os maiores valores no período da tarde. Já no Experimento II as ilhas de calor foram presentes para todos os períodos do dia, com as maiores intensidades também no período da manhã de até $5^{\circ} \mathrm{C}$. As ilhas de frescor foram presentes em todos os horários do episódio, exceto as 4 e 5 horas, se apresentando mais intensas no período da tarde, como ocorreu no Experimento I.

As configurações das ilhas térmicas detectadas pela pesquisa vão ao encontro com o estabelecido por Mendonça (1994, p.13) para as cidades de clima tropical, ou seja, de apresentar ilhas de calor diurnas na época do ano em que há uma maior taxa de insolação e reduzidos valores de umidade. Dessa maneira, é no período da quadra seca na cidade, representado pelo Experimento II, realizado na estação de primavera austral, que as ilhas de calor se manifestaram com a maior freqüência e intensidade do que no Experimento I, período do ano de maior umidade e reduzida insolação, por conta do regime da quadra chuvosa.

Foi detectado uma tendência do Damas e Henrique Jorge - pontos localizados em áreas onde a massa edificada se apresenta de forma mais homogênea, com a ausência de verticalização, com percentual de vegetação bastante reduzida - a apresentar uma maior freqüência de ocorrência de 
ilhas de calor, predominantemente no período diurno. Esse evento pode ser explicado, talvez, pelo rápido aquecimento da massa edificada de estrutura homogênea e, conseqüentemente, o ligeiro aquecimento da temperatura do ar por convecção.

Destaca-se que os elementos de natureza urbana, fluxo de pessoas e veículos, pouco condicionaram o microclima local, não sendo elementos de primeira ordem na modificação térmica dos pontos analisados. Isso porque áreas como Aldeota e Fátima, detentores de elevados valores desses elementos, foram pontos que exibiram baixos valores térmicos e de elevada umidade que, junto com outros pontos como o Cocó, foram em muitos horários da pesquisa presenciadores de ilhas de frescor.

As ilhas térmicas detectadas pela pesquisa apresentaram condição que expressou a realidade da sazonalidade nos períodos de realização dos experimentos, o que demonstrou um efetivo condicionamento da habitualidade climática sazonal na configuração do clima urbano de Fortaleza.

\section{Configurações espaciais das ilhas térmicas na cidade.}

A espacialização das ilhas térmicas foi obtida por meio do Software Surfer versão 8.0. O método de interpolação adotado neste trabalho foi da Krigagem, escolhido por apresentar uma melhor precisão e assumir uma maior fidelidade à base de dados (Landim, Monteiro \& Corsi, 2002). Foi necessária uma sobreposição de um mapa base de Fortaleza para a tomada do contorno geográfico da cidade. Para esse fim, se utilizou da Carta Topográfica da Cidade na escala de 1: 80.000 (FORTALEZA, 2006). Para apresentação desse trabalho houve a necessidade de reduzir essa escala, assim, o produto final apresenta uma escala de aproximadamente 1: 270.000.

As figuras 2 e 3 representam as maiores intensidades das ilhas de calor detectadas pelos experimentos e constatam que o fenômeno é presente, predominantemente, pela manhã na cidade, isso considerando tanto aspectos de freqüência e magnitude. As ilhas de calor apresentaram intensidade para o período entre

$3,5^{\circ}$ até $5^{\circ} \mathrm{C}$. 


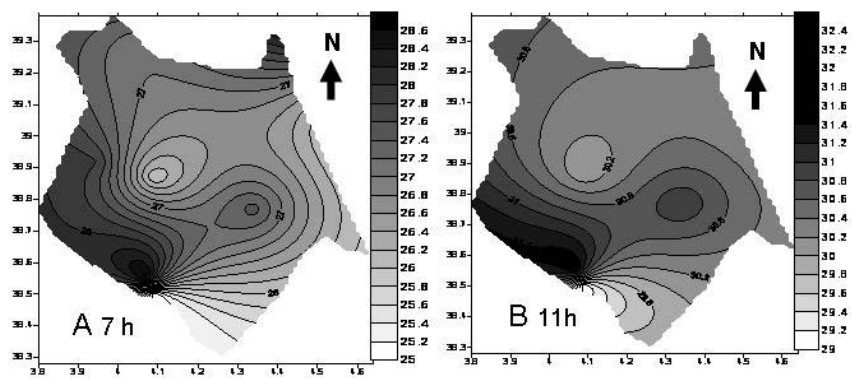

Figura 2 - Configurações do Experimento I : Ilhas de calor no setor oeste e sudoeste da cidade, com intensidade de até $4,7^{\circ} \mathrm{C}$ para o ponto da $\mathrm{B}$ arra do Ceará $(\mathrm{A})$; Ilhas de calor no setor sudoeste com valor de até $3,5^{\circ} \mathrm{C}$ para o ponto do Damas (B).
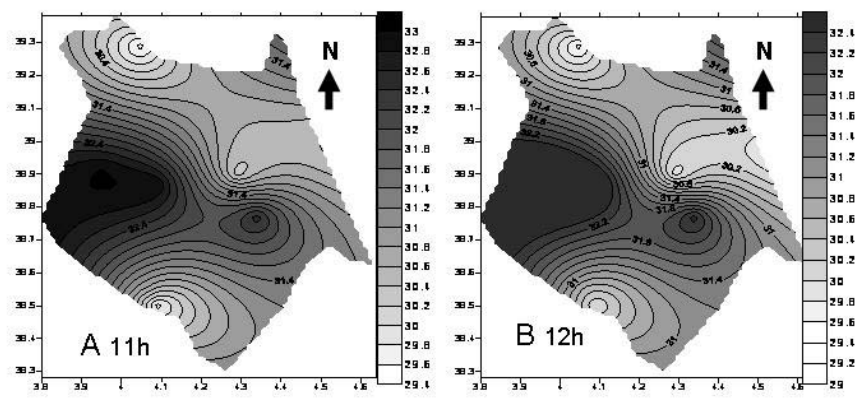

Figura 3 - Configurações do Experimento II: Ilhas de calor no setor oeste e sudoeste e quadrante central da cidade, com intensidade de até $5^{\circ} \mathrm{C}$ para o ponto do Damas (A); $A$ tendência das ilhas de calor no setor sudoeste continuam, também com registro de $5^{\circ} \mathrm{C}$ para $\circ$ bairro Damas (B).

Os setores de maior adensamento urbano da cidade, como o sudoeste, oeste, noroeste e porção central, foram os que presenciaram com mais freqüência, as ilhas de calor. Cabe mencionar que mesmo à noite em alguns horários da madrugada foram esses mesmos setores que também registraram ilhas de calor. Na madrugada não foi detectada configuração de ilhas de frio, isso por conta de uma maior homogeneização das temperaturas que não ultrapassaram os $26,5^{\circ} \mathrm{C}$.

\section{Considerações finais}

As ilhas de calor em Fortaleza ocorreram no período diurno, concentradas no ponto do Damas, e suas configurações, com maior freqüência, ocoreram nos setores sudoeste e porção central da cidade, correspondendo, portanto, os territórios das Regionais Adminstrativas do Município III, IV e 
V. Esses espaços da cidade são áreas de maior massa edificada, porém, sem verticalização, representadas pela regional III e IV, sendo a regional V setor de intensa expansão.

Os mais baixos índices de cobertura vegetal são encontrados nestes setores, exceto em parte da Regional V. Dessa forma, a escassez ou mesmo a ausência da vegetação e de superfícies hídricas e da maior concentração de massa edificada da cidade são em parte, o reflexo das elevadas taxas de densidade demográfica concentradas nos setores sudoeste, oeste, noroeste e na porção central, com o predomínio da categoria de 100 a 170 hab/há, podendo registrar também a categoria de 300 a 370 hab/ha no setor noroeste (Fortaleza, 2006).

A hipótese já colocada anteriormente de que as áreas de grande concentração de massa edificada de aspecto homogêneo é a mais cogitada para explicar o fato dos setores sudoeste, oeste e porção central apresentarem as mais freqüentes e elevadas temperaturas do ar na cidade, isso porque há o rápido aquecimento da massa edificada de estrutura homogênea e, consequentemente, o ligeiro aquecimento da temperatura do ar por convecção, processo que ocorre no período diurno com limite de cessão em torno das 15 horas, isso para a realidade da cidade de Fortaleza, se diferenciando, portanto de áreas com massa verticalizada onde o balanço energético é mais complexo, podendo até favorecer a criação de ambientes condicionados ao conforto.

* O artigo é oriundo de parte dos resultados da Dissertação de Mestrado de Moura (2008) intitulada O Clima Urbano de Fortaleza sob o Nível do Campo Térmico, do Programa de Pós-Graduação em Geografia/UFC.

\section{Referências}

FORTALEZA. Mapas temáticos do Plano Diretor de Desenvolvimento Urbano e Ambiental, 2006. Disponível em <http:// www.seinf.fortaleza.ce.gov.br/PDDU-FOR. Acesso em 18 de novembro 2006.

HISSA, M.C.O estudo do conforto ambiental climático de edifícios multifamiliares em Fortaleza. (Dissertação de Mestrado). Fortaleza: Pós-Graduação Engenharia Civil/ UFC, 2000.

LANDIM, P.M.B; MONTEIRO, R.C; CORSI, A.C. Introdução à confecção de mapas pelo software surfer. Rio Claro. UNESP, Departamento de Geologia Aplicada. 2002. 
MAIA, L.P et al. Alterações climáticas na região de Fortaleza causada por fatores naturais e antrópicos. Revista de Geologia. Fortaleza: UFC, volume 9.

MALVEIRA, E.C.H. Variações de parâmetros climáticos urbanos em Fortaleza no contexto da "Ilha de Calor": sua importância para o desenvolvimento sustentável. (Relatório de Graduação). Fortaleza: Depto. de Geografia - UFC, 1998.

. Estudo de Mudanças Climáticas num ambiente urbano: Evolução da Ilha de Calor na Região Metropolitana de Fortaleza. (Dissertação de Mestrado). Fortaleza: Mestrado Acadêmico em Geografia/ UECE, 2003.

MENDONÇA, F.A. O clima e o planejamento urbano de cidades de porte médio e pequeno: proposição metodológica para o estudo e sua aplicação à cidade de Londrina/PR. .(Tese de Doutorado). São Paulo: FFLCH/USP-Programa de Pós Graduação em Geografia, 1994,

MONTEIRO, C. A. F. Teoria e Clima Urbano. Série Teses e Monografias nº25. São Paulo:Instituto de Geografia/USP, 1976.

. Adentrar a cidade para tomar-lhe a temperatura. In: Revista GEOSUL 9. Florianópolis: Editora da UFSC, 1990.

. O estudo do clima urbano no Brasil. In: Clima urbano Monteiro, C.A.F; MENDONÇA,F

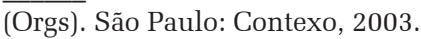

MORENO, G.M.C. Climatología urbana. Textos Docents; 160 Text-guia. Barcelona: Edicions da Universitat de Borcelona, 1999.

MOURA, M.O. Os microclimas urbanos de Fortaleza: ritmos episódicos em duas áreas representativas da cidade. Relatório de Graduação em Geografia. Fortaleza: Departamento de Geografia/UFC,2006.

. O clima urbano de Fortaleza sob o nível do campo térmico. (Dissertação de Mestrado). Fortaleza: Programa de Pós- Graduação em Geografia/UFC, 2008.

OKE,T.R. Boundary Layer Climates- $2^{\text {nd }}$ ed. London: Routledge,1987.

PÉLALAS, K.V. Impactos sobre os parâmetros climáticos em duas áreas de Fortaleza-Ce. (Dissertação de Mestrado). Fortaleza: Pós-Graduação da Engenharia Civil/ UFC, 2000.

PITTON, S.E.C. As cidades como indicadoras de alterações térmicas. (Tese de Doutorado). São Paulo: FFLCH/USP-Programa de Pós Graduação em Geografia, 1997.

PROJETO TEMPOFOR. Estudo microclimático da área central de Fortaleza. Volumes I e II. Fortaleza: Prefeitura Municipal de Fortaleza,1990.

SANTANA, A.M.S. O desenho urbano e a climatologia em Fortaleza. (Dissertação de Mestrado).São Paulo: FFLCH/USP-Programa de Pós Graduação em Geografia,1997.

.A forma urbana e a radiação solar incidente na criação das ambiências térmicas e seus reflexos na apropriação e uso dos espaços públicos externos. (Tese de Doutorado). São Paulo: FFLCH/USP-Programa de Pós Graduação em Geografia,2002.

SOUSA. P.R. Investigação das características de temperatura e umidade do ar da cidade de Fortaleza. (Relatório de graduação) Fortaleza: Depto. de Geografia - UFC, 2002.

XAVIER, T. de Ma. B.S..Alterações climáticas urbanas em Fortaleza/CE. In: IX Congresso Brasileiro de Meteorologia. Campos do Jordão: SBMET, 1996. 
. “Tempo de Chuva”- estudos climáticos e de previsão para o Ceará e o Nordeste Setentrional. Fortaleza: ABC Editora,2001.

ZANELLA, M.E;CLAUDINO-SALES,V. Considerações sobre o clima urbano frente ás emendas propostas à lei do uso e ocupação do solo na cidade de Fortaleza-CE. In: Anais do V Simpósio Brasileiro de Climatologia Geográfica, 2002. CD ROM.

Marcelo de Oliveira Moura - Mestre em geografia pela Universidade Federal do Ceará

Maria Elisa Zanella - Doutora em Meio Ambiente e Desenvolvimento/UFPR e Professora do Departamento de Geografia da Universidade Federal do Ceará

Marta Celina Linhares Sales - Doutora em Geografia Física/USP e Professora do Departamento de Geografia da Universidade Federal do Ceará

Recebido para publicação em novembro de 2008 Aceito para publicação em dezembro de 2008 
